\title{
The predictive effect of medical illnesses for mental health care in adolescence: a register-based study
}

This article was published in the following Dove Press journal:

Adolescent Health, Medicine and Therapeutics

24 August 2017

Number of times this article has been viewed

\author{
Max Karukivi ${ }^{1,2}$ \\ Kirsi-Maria Haapasalo-Pesu ${ }^{3}$ \\ 'Unit of Adolescent Psychiatry, \\ Satakunta Hospital District, Pori, \\ Finland; ' ${ }^{2}$ Department of Psychiatry, \\ Turku University Hospital, University \\ of Turku, Turku, Finland; ${ }^{3}$ Psychiatric \\ Care Division, Satakunta Hospital \\ District, Harjavalta, Finland
}

Background: Adolescence is a developmentally sensitive stage, during which a medical illness may have an effect on individual development, and vice versa. Chronic medical illnesses in adolescents have been associated with psychiatric symptoms. The aim of the present registerbased pilot study was to assess whether, and to what extent, different medical diagnoses predict subsequent use of mental health services among adolescents.

Methods: The study material comprised data on visits to a pediatric clinic by 12 - to 16-year-old adolescent patients over a period of 5 years. Altogether, 10,154 visits by 1,781 patients were identified. The associations of the medical diagnoses with a subsequent visit to the adolescent psychiatry clinic were analyzed using logistic regression.

Results: During the follow-up period, 299 patients (16.8\%) visited or contacted the adolescent psychiatry clinic at least once. Of various diagnoses, the highest odds ratios (ORs) were observed for diabetes mellitus $(\mathrm{OR}=4.07, p<0.001)$ and neoplasms $(\mathrm{OR}=3.29, p=0.047)$. An association was found between adolescent psychiatry clinic visits and female gender.

Conclusion: Medical symptoms and illnesses that require a referral to a pediatrician are a marked risk factor for later use of mental health services. The results call for screening for psychological distress among patients with somatic illnesses and prompt referrals to mental health services if required.

Keywords: adolescents, adolescent psychiatry, medical illness, mental health care, pediatrics

\section{Introduction}

Many adolescents report having regular bodily symptoms, typically from different pains and aches. ${ }^{1}$ Adolescents are also affected by chronic medical illnesses, with the prevalence estimates varying between 10 and $20 \% .{ }^{2}$ Adolescence is a riskful developmental phase in terms of mental health. Compared with childhood, the prevalence of psychiatric disorders in adolescence is approximately twofold, and most lifetime psychiatric disorders are known to originate before adulthood. ${ }^{3}$ Adolescents with chronic illnesses face same developmental challenges as their healthy age-mates. However, there is a reciprocal effect: a chronic illness may have an effect on the adolescent's development and, on the other hand, the development itself may affect the illness. ${ }^{4}$ Therefore, it is not surprising that the risk of emotional and behavioral problems among children and adolescents with chronic illnesses is increased compared with healthy young people. ${ }^{5}$

Although the association between medical illnesses and symptoms of mental illness in adolescence is apparent, to our best knowledge, there are no previous studies comparing medical illnesses in relation to subsequent psychiatric care. The aim of the
Correspondence: Max Karukivi

Unit of Adolescent Psychiatry, Satakunta Hospital District, Itäpuisto II B, FI-28I00 Pori, Finland

Tel +35826274760

Fax +35826274785

Email max.karukivi@utu.fi 
present pilot study was to assess whether and to what extent different medical diagnoses predict later mental health care visits by adolescents.

\section{Methods}

\section{Sample and design}

The data material used in the present study was extracted from the patient information system of the Satakunta Hospital District, Finland. Satakunta is a province with approximately 225,000 inhabitants. The hospital district's pediatric clinic provides specialized health care services for children and adolescents aged $0-16$ years with medical illnesses, and the adolescent psychiatry clinic offers specialized mental health services for 13- to 22-year-olds. The referrals to both the pediatric clinic and adolescent psychiatry clinic typically come from general practitioners and school doctors, but also specialists make referrals to other specialties.

For the present study, we analyzed data on all patient visits to the pediatric clinic to identify adolescents aged from 12 to 16 years who visited the clinic for the first time during the years 2009-2013. Altogether, 10,154 visits by a total of 1,781 patients were identified. Of these patients, 50.6\% $(n=901)$ were female and $49.4 \%(n=880)$ were male. The number of visits by an individual patient ranged from 1 to 100 .

In order to assess to what extent specific illnesses were associated with the later use of mental health services, we identified those patients who had their first visit to the adolescent psychiatry clinic after their visit to the pediatric clinic. The follow-up period ranged from the start of 2009 to the end of 2014. The group comprised 299 patients, of whom $60.5 \%(n=181)$ were female and $39.5 \%(n=118)$ male. For this group, the number of visits to the pediatric clinic ranged from 1 to 57 .

In Finland, registry studies are allowed to deviate from obtaining personal informed consents for specific reasons that would significantly complicate the acquisition. Additionally, the registry data may not be connected with data collected directly from the participants. Since our study design met these criteria, the requirement for personal consents was waived. The study protocol was approved by the Ethical Committee of the Hospital District of Southwest Finland.

\section{Study variables}

The following data were available for the whole sample: gender, age, number and dates of the visits to the pediatric clinic, and the diagnoses made on the visits. Age and gender data were recorded for the first visit. Since a diagnosis was recorded at every visit, for some patients, more than one diagnosis was recorded. The diagnosis codes were based on the ICD-10, and the diagnosis variables on the ICD-10 blocks. ${ }^{6}$ In order to amplify the assessment, the following three core chronic illnesses were assessed separately: asthma (J45), diabetes mellitus (E10-E14), and juvenile rheumatoid arthritis (M08). Due to the aim of the study, diagnosis block F00-F99 "Mental and behavioral disorders" was omitted from the analyses. Additionally, diagnosis block Z00-Z99, which does not represent actual illnesses or symptoms, as well as any diagnosis blocks with 10 or fewer observed diagnoses were omitted.

\section{Statistical methods}

Continuous variables were nonparametrically distributed, and accordingly, characterized using medians and interquartile ranges (IQRs). The group differences between the continuous variables were analyzed using the Mann-Whitney $U$-test. Chi-square tests were applied for categorized variables. The associations of pediatric clinic diagnoses with a subsequent visit to the adolescent psychiatry clinic were analyzed using logistic regression, and the analyses were adjusted for gender and age. The results of the logistic regression analyses are expressed as odds ratios (ORs). In all analyses, $p$-values $<0.05$ were considered statistically significant. Statistical analyses were carried out using SAS System for Windows, version 9.4.

\section{Results}

In the whole sample $(n=1,781)$, the proportion of subjects with a subsequent visit to the adolescent psychiatry clinic $(n=299)$ was $16.8 \%$. On average, these patients had four (median 4.00 , IQR 13.00) visits to the pediatric clinic during the follow-up period, whereas the other patients had three visits (median 3.00, IQR 5.00). The difference was statistically significant $(p<0.001)$. The interval between the first visits to the pediatric and adolescent psychiatry clinics was, on average, 1 year (median 343.00 days, IQR 764.00). The average number of visits to the pediatric clinic before the first adolescent psychiatry visit was three (median 3.00, IQR 6.00).

The subsequent visit to the adolescent psychiatry clinic was significantly $(p<0.001)$ associated with female gender, with the following proportions of the whole sample: $20.1 \%$ ( $n=181$ vs. $n=720)$ for female and $13.4 \%(n=118$ vs. $n=762$ ) for male. Later adolescent psychiatry visits were also related to younger age, but this association did not reach statistical significance $(n=0.076)$. The proportions in the different age groups were as follows: $18.0 \%(n=75$ vs. $n=341)$ for 12 -yearolds, $19.6 \%(n=78$ vs. $n=320)$ for 13 -year-olds, $17.6 \%(n=77$ vs. $n=360)$ for 14 -year-olds, $13.2 \%(n=54$ vs. $n=354)$ for 15 -year-olds, and $12.3 \%(n=122$ vs. $n=107)$ for 16 -year-olds. 
There were marked differences between the ORs for subsequent visits to the adolescent psychiatry clinic for the different medical diagnoses (Table 1). However, the rather small number of cases in some diagnostic blocks resulted in statistically nonsignificant findings.

\section{Discussion}

To our best knowledge, this is the first study among adolescents exploring to what extent different medical diagnoses predict the subsequent use of mental health services. In the present study, one main finding was that every sixth adolescent patient visiting the pediatric clinic had a contact to the adolescent psychiatric clinic during the follow-up period. Two prominent patient groups emerged: patients with a neoplasm and those with a diagnosis of diabetes mellitus.

According to the hospital district's internal evaluations, approximately $5 \%$ of the adolescent population in the province use the services of the adolescent psychiatry clinic, which is in line with the national guidelines for specialized mental health care for adolescent outpatients. ${ }^{7}$ Compared with this, in the present study, the proportion of subjects with a visit to the adolescent psychiatry clinic was approximately threefold. Thus, the existence of such medical illness that requires a referral to a pediatrician appears to be a marked risk factor for later use of mental health services too.

Previous studies have shown that chronic medical illnesses increase the risk for mental disorders in children and adolescents. ${ }^{8}$ In the present study, those who had been diagnosed with diabetes mellitus constituted a prominent group. Indeed, poor diabetic control has been associated to mental health problems. ${ }^{9}$ The relatively highest probability to be referred to the adolescent psychiatry clinic was found among patients with a neoplasm diagnosis. Previous studies have demonstrated that a cancer diagnosis during adolescence will result in significant emotional distress and may be disruptive to the individual's growth process into adulthood. ${ }^{10}$

Asthma and anxiety have been reported to be closely linked also in adolescents. ${ }^{11}$ However, the OR for asthma was rather low in the present study. Since our aim was to identify to what extent medical illnesses predict a later visit to mental health services, the patients with a previous contact to the adolescent psychiatry clinic were omitted from the analyses. Including patients with a prior mental illness would not have enabled the predictive standpoint. Thus, our analysis does not portray the overall linkage between medical illnesses and mental health symptoms. It can be hypothesized that some

Table I The proportions of patients and ORs for a subsequent visit to the adolescent psychiatry clinic according to the pediatric clinic diagnoses

\begin{tabular}{|c|c|c|c|c|c|c|}
\hline \multicolumn{2}{|l|}{ Diagnosis } & \multicolumn{2}{|c|}{$\begin{array}{l}\text { Subsequent visit to } \\
\text { adolescent psychiatric } \\
\text { clinic }\end{array}$} & \multirow[t]{2}{*}{ OR } & \multirow[t]{2}{*}{$95 \% \mathrm{Cl}$} & \multirow[t]{2}{*}{$p^{b}$} \\
\hline Title & $\begin{array}{l}\text { Diagnosis } \\
\text { block }^{\mathbf{a}}\end{array}$ & Yes, n (\%) & No, n (\%) & & & \\
\hline Diabetes mellitus & EI0-EI4 & $55(39.3)$ & $85(60.7)$ & 4.07 & $2.79-5.94$ & $<0.001$ \\
\hline Neoplasms & C00-D48 & $5(4 \mid .7)$ & $7(58.3)$ & 3.29 & $1.02-10.62$ & 0.047 \\
\hline Diseases of the circulatory system & $100-199$ & $10(23.3)$ & $33(76.7)$ & 1.61 & $0.78-3.33$ & 0.20 \\
\hline Juvenile rheumatoid arthritis & M08 & $13(19.1)$ & $55(80.9)$ & 1.09 & $0.59-2.05$ & 0.78 \\
\hline Diseases of the genitourinary system & N00-N99 & $6(18.8)$ & $26(8 I .2)$ & 1.08 & $0.44-2.66$ & 0.87 \\
\hline Symptoms, signs, and abnormal findings, not elsewhere classified & R00-R99 & $51(17.6)$ & $239(82.4)$ & 1.02 & $0.73-1.42$ & 0.92 \\
\hline $\begin{array}{l}\text { Diseases of the musculoskeletal system and connective tissue } \\
\text { (disregarding juvenile rheumatoid arthritis) }\end{array}$ & $\begin{array}{l}\text { M00-M07, } \\
\text { M30-M99 }\end{array}$ & $25(18.7)$ & $109(81.3)$ & 0.99 & $0.62-1.57$ & 0.96 \\
\hline $\begin{array}{l}\text { Diseases of the blood and blood-forming organs; certain immune } \\
\text { mechanism disorders }\end{array}$ & D50-D89 & $5(17.2)$ & $24(82.8)$ & 0.94 & $0.35-2.50$ & 0.90 \\
\hline $\begin{array}{l}\text { Endocrine, nutritional, and metabolic diseases (disregarding diabetes } \\
\text { mellitus) }\end{array}$ & $\begin{array}{l}\text { E00-E09, } \\
\text { E20-E90 }\end{array}$ & $34(12.9)$ & $230(87.1)$ & 0.71 & $0.48-1.04$ & 0.078 \\
\hline Diseases of the digestive system & K00-K93 & $17(12.5)$ & $119(87.5)$ & 0.68 & $0.40-1.16$ & 0.16 \\
\hline $\begin{array}{l}\text { Congenital malformations, deformations, and chromosomal } \\
\text { abnormalities }\end{array}$ & Q00-Q99 & $8(11.0)$ & $65(89.0)$ & 0.62 & $0.29-1.31$ & 0.21 \\
\hline Diseases of the respiratory system (disregarding asthma) & J00-J44, J46-J99 & $15(10.5)$ & $128(89.5)$ & 0.54 & $0.31-0.94$ & 0.030 \\
\hline Asthma & $\mathrm{J} 45$ & $17(9.4)$ & $163(90.6)$ & 0.50 & $0.30-0.83$ & 0.008 \\
\hline Certain infectious and parasitic diseases & A00-B99 & $5(8.5)$ & $54(91.5)$ & 0.47 & $0.18-1.18$ & 0.11 \\
\hline Diseases of the nervous system & G00-G99 & $2(6.9)$ & $27(93.1)$ & 0.38 & $0.09-1.62$ & 0.19 \\
\hline Diseases of the skin and subcutaneous tissue & L00-L99 & $2(5.7)$ & $33(94.3)$ & 0.28 & $0.07-1.18$ & 0.084 \\
\hline
\end{tabular}

Note: anternational Statistical Classification of Diseases and Related Health Problems IOth Revision. ${ }^{\mathrm{b}}$ Logistic regression analysis, adjusted for gender and age. Abbreviations: $\mathrm{OR}$, odds ratio; $\mathrm{Cl}$, confidence interval. 
patients with asthma already had a contact to mental health services, which diluted the OR.

Although bodily symptoms appear to be somewhat more common in female, ${ }^{1}$ the whole sample included an equal amount of girls and boys. However, the patients with subsequent use of mental health services were more often female. Previously, Surís et al found that chronically ill girls were more likely to have emotional problems than their healthy counterparts, but the same was not true for boys. ${ }^{12}$ Although the association did not quite reach statistical significance, the proportion of the referred patients declined with age. This highlights the importance of early adolescence as a critical phase of development; it is a time of accelerated growth and changing moods, and with characteristic developmental changes on a neurobiological level. ${ }^{13}$

\section{Limitations}

The present study has some limitations. The study setting allowed us only to explore the chronological relation of the visits to the pediatric and adolescent clinics, and it precludes the possibility to draw any conclusions about causality. Additionally, it was not possible to assess whether the referral to the adolescent psychiatry clinic was made from the pediatric clinic or elsewhere. The number of variables was limited, and therefore, several factors may influence the findings. Our approach facilitated a comprehensive overview of the different diagnoses, but the small number of cases in some diagnostic blocks resulted in nonsignificant findings. Additionally, due to incomplete data, we were not able to further assess the visits to the adolescent psychiatry clinic.

\section{Conclusion}

It is apparent that many adolescents with medical illnesses have challenges in coping and adapting to life with a chronic disease. Pediatricians and others professionals should be encouraged to screen adolescents with chronic medical illnesses for symptoms of psychological distress, and if necessary, make appropriate referrals to mental health services. ${ }^{14}$

\section{Disclosure}

The authors report no conflicts of interest in this work.

\section{References}

1. Romero-Acosta K, Canals J, Hernández-Martínez C, Penelo E, Zolog TC, Domènech-Llaberia E. Age and gender differences of somatic symptoms in children and adolescents. J Ment Health. 2013;22(1):33-41.

2. Sawyer SM, Drew S, Yeo MS, Britto MT. Adolescents with a chronic condition: challenges living, challenges treating. Lancet. 2007;369(9571):1481-1489.

3. Kessler RC, McGonagle KA, Zhao S, et al. Lifetime and 12-month prevalence of DSM-III-R psychiatric disorders in the United States. Results from the National Comorbidity Survey. Arch Gen Psychiatry. 1994;51(1):8-19.

4. Suris JC, Michaud PA, Viner R. The adolescent with a chronic condition. Part I: developmental issues. Arch Dis Child. 2004;89(10):938-942.

5. Pinquart M, Shen Y. Behavior problems in children and adolescents with chronic physical illness: a meta-analysis. J Pediatr Psychol. 2011;36(9):1003-1016.

6. World Health Organization. International Statistical Classification of Diseases and Related Health Problems, ICD 10, Vol 1. Geneva: WHO; 1992.

7. Pylkkänen K. Nuorisopsykiatrisen avohoidon laatusuositus [The Guidelines for Outpatient Care in Adolescent Psychiatry]. Helsinki: Finnish Association of Adolescent Psychiatry; 2013. Finnish.

8. Bennett S, Shafran R, Coughtrey A, Walker S, Heyman I. Psychological interventions for mental disorders in children with chronic physical illness: a systematic review. Arch Dis Child. 2015;100(4):308-316.

9. Pless B, Nolan T. Revision, replication and neglect - research on maladjustment in chronic illness. $J$ Child Psychol Psychiatry. 1991;32(2):347-365.

10. Prasad PK, Hardy KK, Zhang N, et al. Psychosocial and neurocognitive outcomes in adult survivors of adolescent and early young adult cancer: a report from the childhood cancer survivor study. JClin Oncol. 2015;33(23):2545-2552.

11. Bruzzese JM, Reigada LC, Lamm A, et al. Association of youth and caregiver anxiety and asthma care among urban young adolescents. Acad Pediatr. 2016;16(8):792-798.

12. Surís J, Parera N, Puig C. Chronic illness and emotional distress in adolescence. J Adolesc Health. 1996;19(2):153-156.

13. Paus T, Keshavan M, Giedd JN. Why do many psychiatric disorders emerge during adolescence? Nat Rev Neurosci. 2008;9(12):947-957.

14. Pinquart M, Shen Y. Depressive symptoms in children and adolescents with chronic physical illness: an updated meta-analysis. $J$ Pediatr Psychol. 2011;36(4):375-384.
Adolescent Health, Medicine and Therapeutics

Publish your work in this journal

Adolescent Health, Medicine and Therapeutics is an international, peer-reviewed, open access journal focusing on health, pathology, and treatment issues specific to the adolescent age group. All aspects of health maintenance, preventative measures and disease treatment interventions are addressed within the journal and practitioners from all disciplines are

\section{Dovepress}

invited to submit their work as well as healthcare researchers and patient support groups. This journal is included in PubMed. The manuscript management system is completely online and includes a very quick and fair peer-review system. Visit http://www.dovepress.com/testimonials. php to read real quotes from published authors. 